\title{
Doença Mental, Raça e Sexualidade nas Teorias Psiquiátricas de Juliano Moreira ${ }^{1}$
}

ANA TERESA A. VENANCIO ${ }^{2}$

\section{RESUMO}

Tomando como ponto de partida a representação erudita que situa Juliano Moreira como fundador da psiquiatria científica no Brasil, este trabalho analisa as concepções por ele veiculadas sobre doença mental, raça e sexualidade. Suas teorias constituíram uma transposição sui generis do pensamento do psiquiatra alemão Emil Kraepelin, ajudando na construção do ideário em prol do processo civilizatório brasileiro no início do século XX. Fundamentava-se em pressupostos organicistas, ao mesmo tempo em que se contrapunha à idéia corrente na época sobre as condições "naturais" brasileiras desfavoráveis como o clima e a raça. Analisando os trabalhos publicados por Juliano Moreira até 1920, relaciona-se aqui o modo como seu discurso científico discutia o tema da sexualidade, expressa sob a rubrica da "sífilis", da "reprodução" e do "casamento". Com relação a essa temática, Juliano Moreira não se valeu da idéia de uma natureza feminina degenerada, crescentemente difundida em meados do século XIX. Ainda que não desconsiderasse a idéia mais geral da degeneração, pertinente apenas ao nível das unidades orgânicas individuais, descartaria a correlação entre degeneração e natureza feminina, para se ater aos fundamentos médicos hegemônicos na primeira metade do século XIX, que articulavam as marcas diferenciais da mulher à sua fisiologia sexual, paradigmaticamente representada pela imagem do útero.

Palavras-chave: Raça; sexualidade; doença mental; ciência psiquiátrica; Juliano Moreira. 


\section{Introdução}

Este artigo analisa as representações sobre doença mental, raça e sexualidade veiculadas nos artigos do psiquiatra Juliano Moreira escritos em fins do século XIX até 1920. A escolha dessas categorias não é de modo algum fortuita e visa a articular dois níveis analíticos. Trata-se, de um lado, da análise de duas vias privilegiadas de construção social da diferença - doença mental e sexualidade - que as sociedades ocidentais modernas têm utilizado para qualificar os indivíduos que as compõem. De outro lado, busca enveredar sobre o modo como, historicamente, a idéia de raça esteve presente no discurso científico psiquiátrico, considerando-se sua centralidade na auto-representação de uma nação brasileira.

Ainda que tais níveis analíticos, para efeito expositivo, estejam assim separados, as três categorias tomadas para análise possuem, como veremos, pontos de conexão importantes: as representações sobre a mistura de raças e a hiperestesia sexual do brasileiro, as teorias psiquiátricas que associavam doença mental e constituição racial do brasileiro e os debates em torno das possibilidades de incluir o Brasil no conjunto das sociedades ocidentais modernas que, por suas condições climáticas e populacionais, por muito tempo vem se constituindo como o "outro", diferente e exótico. Desse modo, o primeiro nível analítico, em que se privilegiam temas da doença mental e da sexualidade, só assume sentido pleno para os objetivos deste trabalho se articulado às representações sobre a construção social da diferença pela raça que, historicamente, vêm dando textura a um ideal de brasilidade. Nessa perspectiva, as categorias em análise - doença mental, sexualidade, raça e nação brasileira - não têm aqui seus conteúdos simbólicos definidos a priori - queremos antes conhecê-los.

Não se trata, entretanto, da análise de qualquer modo representacional, mas daquele que, considerado científico, tem sido eleito pelo ideário moderno como o mais legítimo para semear seus frutos. Levando-se a sério, portanto, a máxima antropológica de que o estudo de uma cultura ou sociedade deve considerar os próprios termos que esta privilegia ou nos quais se funda, este artigo busca entrelaçar como objetos as ênfases "nativas" concedidas à ciência e à história, a fim de compreender a complexidade dos investimentos e significados que têm procurado inscrever o Brasil nas sociedades ocidentais modernas $^{3}$. 
No que diz respeito à ciência, a expressão no singular não visa a tomála como um bloco monolítico, mas considerar que, em todas as disputas teóricas e políticas que a constituem e são por elas constituídas, em suas diferentes expressões e em todo o processo crescente de suas especializações - da qual a ciência psiquiátrica é um exemplo -, o que está em jogo é a constituição de uma verdade científica unívoca que se contrapõe a outros saberes e representações sobre o humano, considerados leigos ou não suficientemente eruditos para retratar o processo em direção à "civilização", ao "progresso", "desenvolvimento" ou "globalização" almejado pelas sociedades modernas.

A adoção da história, por sua vez, objetiva exatamente sinalizar as distorções que o imaginário científico e suas descobertas triunfantes nos impõem. Mais que isso, quer debater as duas possibilidades analíticas sobre as quais a visão de mundo moderna, na qual se inserem objeto e sujeito dessa investigação, nos enreda. De um lado, a abordagem que concebe a história com as lentes de nossa razão iluminista - na qual se insere a visão científica - e que, em última instância, tende sempre a ver o passado como aquilo que nos condena e nos impede de seguir o destino irrevogável ao futuro. De outro, a perspectiva que poderíamos chamar de romântica, por vislumbrar em todo novo evento apenas um "retorno" ao antigo, às raízes, reatualizações de totalidades culturais e simbólicas mais afeitas a uma essência imutável. Colocar em debate as duas possibilidades de olhar para a história é tentar perceber as rupturas e continuidades que são, ao mesmo tempo e paradoxalmente, estabelecidas nos processos socioculturais que conformamos e que nos conformam.

Para fins desta análise, portanto, a ciência psiquiátrica é entendida como o saber científico que desde sua constituição, na aurora do século XIX, concedeu estatuto diferencial a uma doença específica, porque mental. Tratase de uma medicina de tipo especial, forjada na tensão entre a atenção às dimensões física individual e moral e que, por essa via, conforma seu objeto como uma das formas modernas de diferenciação social: a diferença instituída na loucura tornada doença mental (FOUCAULT, 1978). Essa tensão inarredável presente na constituição e desenvolvimentos do conhecimento psiquiátrico traduz o modo próprio de observação / compreensão do humano em termos do dualismo cartesiano corpo / mente, ainda que as ênfases, historicamente distintas, dadas pela ciência psiquiátrica a uma ou outra dessas esferas do humano, venham produzindo modos particulares de representação da Pessoa individualizada e de sua relação com os planos da natureza e da cultura. 
Assim como o tema da doença mental, a sexualidade aparece como um dos principais veículos para a construção social do sujeito moderno, tendose constituído a partir do século XVIII como um domínio desvinculado, clara e gradualmente, de um universo simbólico mais abrangente que incluía os fenômenos da sensibilidade e da sensualidade. A construção histórica da sexualidade e da verdade a ela atribuída girou, assim, em torno de três aspectos fundamentais: a perfectibilidade, a preeminência da experiência e o fisicalismo (DUARTE, 1999, p. 24).

Já no cristianismo encontramos uma vinculação entre verdade sobre o humano e os desejos corporais / sexuais. Essas raízes cristãs permanecem na moderna configuração de valores, mas o foco representacional na "alma individual" em relação a Deus é deslocado para a unidade singular isenta de qualquer transcendência, colocando-se a possibilidade de produção do mundo social a partir da própria autodefinição dos indivíduos (FOUCAULT \& SENNET, 1981). Desde então, o tema da sexualidade vem sendo crescentemente produzido por práticas e discursos (científicos e não-científicos), comprometidos com os ideários do "conhecer a si mesmo", do "cuidado de si" e do "pôr em discurso" (FOUCAULT, 1988). É exemplar, nesse sentido, o modo como, na cultura ocidental moderna, a sexualidade é parâmetro de aferição das características humanas a partir do sentido de verdade sobre nós mesmos que a ela imputamos. Tal verdade é construída com base numa solução que assim como no caso da doença mental - está atenta a um só tempo para as dimensões do corpo e da mente. É dessa zona de interstício entre a fisicalidade e a moral (individual e social) que a sexualidade se depreendeu e onde se fixou. ${ }^{4}$

\section{Ciência Psiquiátrica, Pensamento Sanitarista e a Questão Racial}

A centralidade de Juliano Moreira (1873-1933) na história da psiquiatria brasileira tem sido atribuída pelo imaginário erudito como decorrência dos cargos importantes que assumiu em sua vida profissional e da ênfase que concedeu a uma "psiquiatria científica", publicando considerável número de trabalhos em diferentes periódicos de renome ${ }^{5}$. Numa primeira fase, que podemos chamar de "tropicalista", seus artigos versaram mais sobre doenças como a leishmaniose, sífilis, malária e ainhum ${ }^{5}$. Destacava sua preocupação com a divulgação das mais recentes descobertas no campo da medicina, com o valor da ciência e com o desenvolvimento de estudos continuados, para seu fortalecimento e bom 
"estabelecimento de conclusões racionais" (MOREIRA, 1898, p. 250). Com esse olhar estritamente científico, Juliano Moreira divulgava trabalhos europeus já existentes sobre as doenças típicas dos climas quentes, questionando, entretanto, a inexorabilidade da relação de tais doenças com o clima e a raça.

$\mathrm{Na}$ segunda fase de sua produção intelectual, marcada pela atenção especial à "clínica" psiquiátrica, J. Moreira foi influenciado pela psiquiatria alemã de base organicista, capitaneada por Émil Kraepelin, formulando propostas afirmativas desse conhecimento científico especializado e de novos modelos assistenciais ${ }^{7}$. Observa-se, por parte de Juliano Moreira, a adoção dos princípios classificatórios que o psiquiatra alemão havia reunido - os sintomas considerados em termos de sua etiologia e a evolução da doença - incluindo-se aí a proposição de uma classificação psiquiátrica brasileira ancorada, sobremaneira, no caráter universal concedido às categorias diagnósticas kraepelinianas (VENANCIO e CARVALHAL, 2001).

Assim como Kraepelin, Juliano Moreira concebia a doença mental como um estado de natureza diferenciada dos estados ditos normais. Do ponto de vista de Juliano Moreira, portanto, a doença mental, "como desvio da normalidade que é, é uma exceção biológica” (MOREIRA, 1919, p. 93) e, nesse sentido, só poderia ser observada mediante a consideração preponderante da esfera orgânica do indivíduo. Na verdade tratava-se aqui, como em Kraepelin, da tentativa de produção de uma síntese entre a etiologia moral e física, tomandose o determinismo físico-orgânico como englobante de uma provável etiologia moral. A causalidade é remetida, assim, à ação de toxinas sobre o córtice cerebral, associada a perturbações gerais do organismo, que se manifestariam em sintomas. Nesse modelo, os sintomas das doenças mentais, remetidos a afecções da vontade e da consciência, eram considerados do ponto de vista organicista, sem nenhuma consideração que problematizasse as questões morais do livre arbítrio individual ou da existência de uma "divisão de si" gerada por motivações idiossincráticas. Tratava-se da consciência e vontade produzidas por reações motoras, isto é, pelo substrato físico propiciador ou impeditivo da atuação psicomotora individual (MOREIRA, 1901, p. 43) - fisicalidade determinante para a expressão das capacidades de afeto, de julgamento e, por conseguinte, da própria totalidade individual representada pela personalidade ${ }^{8}$.

A ênfase nos estudos da especialidade psiquiátrica, entretanto, não deixaria de lado temas presentes na primeira fase do pensamento de Juliano Moreira. Ao contrário, a consolidação da psiquiatria participaria da discussão 
dos temas do clima e da constituição racial. Desde o período colonial, a natureza hostil era vista por cronistas, naturalistas e médicos como obstáculo à civilização nos trópicos. O nascente ideário higienista, cuja institucionalização se daria a partir de 1829, atualizaria a visão sobre nossas condições socioambientais e as patologias daí decorrentes. Relacionado à medicina neo-hipocrática, o higienismo estava articulado a uma concepção ambientalista da medicina, fundamentada na hipótese da relação intrínseca entre doença, ambiente e sociedade (FERREIRA, 2001, p. 207-208). A preocupação sanitária com a cidade do Rio de Janeiro seria referida a duas ordens de problemas, que não incluíam a questão racial: os miasmas, produzidos pelo clima associado à topografia geográfica, e o estado sanitário propriamente dito, traduzido na falta de tratamento de esgoto e lixo, na estagnação das águas das chuvas na poluição pluvial e nas péssimas condições habitacionais (MAIO, 2004, p. 18).

Ao longo da década de 1870, entretanto, alguns dos fundamentos da tradição neo-hipocrática passariam a ser questionados, tendo-se em vista o novo ideal científico ancorado na medicina experimental pasteuriana, que discorria sobre as etiologias parasitárias. Contudo, o que Maio destaca, baseado em outros autores, é que esses saberes acabaram se entrelaçando, de modo que médicos representantes do higienismo se apropriaram dos novos métodos científicos para dar conta das marcas tropicais que assolavam o país (MAIO, 2004, p. 24-25). Já nas duas primeiras décadas do século XX, "momento em que explode o debate sobre a saúde pública, o higienismo - assentado em princípios da bacteriologia e da microbiologia - manteve elos de continuidade com o ideário neo-hipocrático, no que tange à recusa a chaves explicativas de natureza racial" (MAIO, 2004, p. 17-18). Portanto, o higienismo e todo o movimento em prol do saneamento da cidade do Rio de Janeiro, observados na aurora do século XX, não estiveram fundados em conteúdos deterministas raciais, ainda que as teorias e explicações racistas vicejassem em várias outras esferas eruditas, dentre elas parte do conhecimento psiquiátrico, como veremos a seguir.

Seria, entretanto, a essa visão pessimista sobre uma inexorável constituição racial do brasileiro, muitas vezes associada à imutabilidade climática e seus efeitos deletérios, que Juliano Moreira se oporia. A entrada de Juliano Moreira na direção do Hospício Nacional de Alienados coadunava-se com o processo de saneamento urbano da cidade durante a gestão do prefeito Pereira Passos (1902-1906). Os novos rumos para o campo da medicina mental integravam as diretrizes da saúde pública, que iam do alargamento das ruas e 
demolição de habitações precárias a uma intensa campanha de vacinação e profilaxia das doenças, promovida por Oswaldo Cruz, então diretor-geral de Saúde Pública. A atuação de Juliano Moreira no referido hospital vinha reforçar tais iniciativas "modernizadoras", ampliando-as para essa esfera da assistência pública - a dos alienados - corroborada pelo projeto de desenvolvimento de uma ciência psiquiátrica brasileira.

É em relação, portanto, a esse panorama de idéias e práticas, que os esforços de Juliano Moreira em prol de uma psiquiatria científica brasileira atestariam que aqui, como além-mar, estávamos do mesmo modo fadados a abrigar indivíduos doentes mentais, refutando, por essa via, a idéia de uma hierarquia dos povos pautada na diferença entre países de climas variados ou formações raciais diversificadas. Moreira \& Peixoto (1906) desenvolveriam a tese de que não existem doenças mentais climáticas, afirmando que os climas tropicais em si não dariam origem naturalmente a mais ou menos casos dessa moléstia. Na perspectiva desses autores, a incidência de neurastenia e histeria no Brasil, por exemplo, não era diferente dos índices encontrados na Europa e na América do Sul, mesmo considerando-se que formas convulsivas da histeria poderiam se tornar epidemias, como a da Astasie-Abasia, em São Luís do Maranhão, de 1879-1881. São recorrentes as afirmações sobre a importância de um meio social saudável e uma educação eficaz na prevenção do possível aparecimento de doenças mentais.

"O clima não influi em nada sobre os sintomas de diversas psicoses. É no grau de instrução do indivíduo que reside a causa das diferenças que podem se apresentar. O descendente puro de dois caucasianos, igualmente puros, criados no interior no meio de pessoas ignorantes, apresentam os mesmos delírios rudimentares que os indivíduos de cor desprovidos de instrução" (MOREIRA e PEIXOTO, 1906, p. 238 - tradução minha).

Diferentemente de Juliano Moreira, entretanto, o conhecimento psiquiátrico da época estabelecia uma relação de determinação entre raça e aparecimento de doença mental. Nina Rodrigues (1862-1906), um dos maiores expoentes da nascente psiquiatria brasileira, da medicina legal e da antropologia - num período em que tais disciplinas estavam entrelaçadas - discutiria a relação entre loucura e crime, utilizando para tanto o aporte teórico da noção de degeneração e de sua correlação com a miscigenação racial. Para Nina Rodrigues, a distinção racial era importante para a compreensão das doenças físicas e mentais, considerando-se que as raças transmitiriam "os produtos de 
seus cruzamentos caracteres patológicos diferenciais de valor" (RODRIGUES, 1939, p. 203). Segundo Oda (2001), para Nina Rodrigues:

"a inferioridade racial dos negros e indígenas com relação ao branco era indiscutível; assim sendo, a miscigenação entre raças em diferentes patamares evolutivos resultaria, fatalmente, em indivíduos desequilibrados, degenerados, híbridos do ponto de vista físico, intelectual e nas suas manifestações comportamentais" (ODA, 2001, p. 3).

Juliano Moreira, por sua vez, negaria a correlação entre degeneração e constituição racial, apontando que a etiologia da primeira decorria de outros fatores causais: o alcoolismo, a sífilis e as condições educacionais e sanitárias precárias. Como representante do pensamento sanitarista no campo psiquiátrico, defenderia medidas profiláticas que, entretanto, não tinham uma conotação racista (ODA, 2001, p. 6). O que Juliano Moreira propunha era uma visada sobre a igualdade das raças, que possibilitaria a inclusão do miscigenado povo brasileiro num projeto universalista de desenvolvimento. É exemplar, nesse sentido, a apresentação que faz de um doente mental, mãe mulata sem graves patologias e pai italiano:

\footnotetext{
"Tendo demonstrado este doente ao Prof. Nina Rodrigues, achou ele no caso mais uma prova de que a mestiçagem é um fator degenerativo. Ora, tendo eu sempre me oposto a esta maneira superficial de ver o problema, aproveitei uma longa estada na Europa para examinar os parentes de A.P.D. que tinham ficado na Europa, livres da mestiçagem [...] vê-se pois que o ramo europeu da família, livre da mestiçagem, em nada foi superior ao ramo mestiço brasileiro" (MOREIRA, 1908, p. 431-432).
}

Com isso Juliano Moreira atestava que, embora houvesse uma diferença entre nós e os países europeus - dada por nossas ainda incipientes condições sociais - tal diferença não era irrefutável, podendo ser aplacada pela construção de uma sociedade mais civilizada. O que estava em jogo era a prospecção de sociedade em que, pelas vias da educação e da produção de um meio social saudável, os indivíduos poderiam se constituir como moralmente iguais e passíveis de serem influenciados por uma moralidade civilizada; combatendo-se, dessa forma, as diferenças irredutíveis presentes apenas na dimensão físico-orgânica dos indivíduos. O pensamento de Juliano Moreira sobre a dimensão físicoorgânica das doenças mentais, suas causas e evolução, coadunava-se com uma perspectiva inovadora para o pensamento psiquiátrico brasileiro. Tratava- 
se da defesa de um projeto de sociedade moralmente igualitária e profilática em relação às possíveis diferenças físico-orgânicas individuais que, apesar de poderem atingir uma parcela da população, eram independentes do clima e da constituição racial.

\section{Doença Mental e Sexualidade no Pensamento de Juliano Moreira}

É no contexto das discussões de fins do século XIX sobre a sífilis e os males dela decorrentes que Juliano Moreira relacionou doença mental e sexualidade ${ }^{9}$. Como sabemos, durante o século XIX e as primeiras décadas do século XX, o tema da sífilis ocupou o pensamento médico brasileiro, servindo ao desenvolvimento de teorias e assertivas sobre a posição do Brasil no conjunto das nações civilizadas. Ao mesmo tempo em que, para o discurso médico europeu, a sífilis era considerada um mal universal que grassava por todos os povos, aparecia como um mal maior específico do povo brasileiro, segundo os debates em torno de três temáticas: a crença em sua origem americana, a sua maior disseminação no Brasil e o caráter mais avassalador que suas manifestações aqui assumiam, se comparado a outros países (CARRARA, 1997, p. 392).

O primeiro tema estava relacionado à assunção de uma ou outra concepção sobre a etiologia e desenvolvimento da sífilis - em ambos os casos, com base no neo-hipocratismo. Se considerada decorrente de outra doença, de fatores climáticos ou de evento inflamatório produzido por uma irritação dos órgãos sexuais pela repetição do ato em condições anti-higiênicas, a hipótese da origem americana era passível de ser descartada; o argumento era o de que a vida sexual desregrada ou imoral não era um atributo específico dos povos americanos. Se articulada às concepções contagionistas, entretanto, a origem americana da sífilis aparecia como mais facilmente demonstrável.

"Embora nem todos os contagionistas fossem partidários da hipótese americana, todos os que defendiam a origem americana do mal supunham necessariamente seu caráter contagioso. Pode-se mesmo acreditar que, depois da 'revolução pasteuriana', com a vitória indiscutível dos contagionistas, a consolidação da hipótese americana tenha recebido contribuição decisiva" (CARRARA, 1997, p. 394).

Mesmo nesse caso, durante a primeira metade do século XX, muitos 
especialistas brasileiros iriam afirmar que, embora originada no Brasil, a sífilis teria sido aqui implantada pelos europeus a partir do descobrimento.

Segundo Carrara (1997), os dois outros temas - a maior disseminação no contexto brasileiro e a especificidade mais maligna de uma "sífilis tropical" - também seriam discutidos pelo pensamento médico brasileiro, no sentido de se reordenar simbolicamente os argumentos que impediam o Brasil de entrar no rol das nações civilizadas. Os caminhos trilhados para essa reordenação simbólica fundamentavam-se, de um lado, em discussões científicas sobre os erros diagnósticos decorrentes da indistinção da sífilis em relação a outras doenças, principalmente as dermatoses. De outro lado, os sifilógrafos brasileiros reproduziam a idéia de uma extensa disseminação do mal venéreo no país apoiados em grande medida em sua experiência clínica e informações obtidas junto à população hospitalizada - e reivindicavam campanhas públicas nacionais que extinguissem a doença (CARRARA, 1997, p. 400).

Como bem aponta Carrara (1997), até a década de 1920 a hiperestesia sexual do brasileiro associava-se de modo estreito com a hipótese da maior disseminação da sífilis no país, ambas ancoradas em fatores explicativos como clima e raça. A partir dos anos de 1920, entretanto, a relação entre mal venéreo e o hipersexualismo do brasileiro deixa, paulatinamente, de ser explicada por razões climatológicas e raciais, a exemplo das críticas ao tema da origem americana da sífilis: nem o clima, nem a raça determinariam a localização primeira da sífilis no Brasil ou a hiperestesia sexual do povo brasileiro. A sífilis e o "apetite sexual" excessivo do brasileiro adviriam de seu componente racial branco, os portugueses, e de fatores morais - individuais e sociais -, como a falta de "domínio sobre si próprio", a ignorância, a pobreza, a imoralidade do meio social e a herança escravocrata. A partir dos anos de 1920, o imaginário sobre a degeneração a que estaria submetido o povo brasileiro não era mais hegemonicamente pautado na miscigenação racial, mantendo-se, contudo, o argumento último da hiperestesia sexual e de seu caráter patológico (CARRARA, 1997, p. 403-404).

Muitas das idéias que Carrara (1997; 2004) nos apresenta sobre o modo como a questão sexual, a partir da polimorfia da sífilis, foram expressas pelo pensamento médico brasileiro, podem também ser observadas nos estudos de Juliano Moreira sobre o tema. O que Moreira $(1895 ; 1899)$ apresenta em seus dois textos sobre a sífilis é a representação de um mal universal, que não acometeria apenas as mentes e corpos brasileiros, como demonstrava através 
de inúmeros casos encontrados em diferentes países: Brasil, Alemanha, Inglaterra, França. Essa idéia mais geral introduziria em seus trabalhos a força argumentativa de uma visada científica do problema, pois só esse tipo específico de conhecimento poderia falar das características gerais da doença, comprovar sua etiologia e desenvolvimento e prover sua cura. Ainda que as linhas escritas pelo psiquiatra nos revelem o imaginário mais geral da época, de que "há brasileiro que não tenha sua tara sifilítica?" (MOREIRA, 1895, p. 37), a argumentação científica aqui se desdobrava para afirmar que há que se distinguir a sífilis de outras doenças, sobretudo as dermatoses, de modo a conceder ao mal sua justa feição, tratamento e dimensão - mesmo que para confirmar que se tratava de um dos maiores males que assolava nossa população.

Entretanto, como veremos no que segue, Juliano Moreira aqui também discordaria das hipóteses climáticas e raciais em torno da sífilis. Assim como seus outros trabalhos, "Culpabilidade dos syphiliticos que se casam" - publicado em 1895 na Revista Médico-Legal, órgão oficial da Sociedade de Medicina Legal da Bahia - atestava um inarredável compromisso com a ciência e a medicina pública como "os naturais diretores do espírito das maiorias" (MOREIRA, 1895, p. 36). Analisando "os sifilíticos em relação à sociedade", propunha, como resultado da combinação entre medicina legal e higiene, a punição dos infratores que ameaçassem as "boas leis profiláticas".

Em seu texto, o tema da sexualidade aparece representado por duas vias diferentes que falam, respectivamente, sobre as leis sociais e morais que legitimariam o ato sexual e sobre a especificidade da fisiologia sexual feminina, quais sejam: o casamento e o útero. Explicitava que ia se referir "ao problema da sífilis em suas relações com o casamento" (MOREIRA, 1895, p. 36) e que a sífilis se tornava um mal maior para a saúde pública quando contraída pelo casamento, tendo-se em vista a contaminação do homem para a mulher e as conseqüências para as gerações futuras. Referindo-se ao problema da sífilis, atribuía ao pai da jovem e a seu futuro marido o papel de se informarem sobre o mal venéreo:

\footnotetext{
"ao pai da jovem brasileira tudo lembra, menos saber se aquele que pretende esposar-lhe a filha é ou não um sifilítico. [...] O marido pode, qual funesto presente de núpcias, transmitir sua sífilis a sua companheira de lar, seja por contágio direto: cancro primitivo, lesões secundárias. Seja por contágio indireto, provocado pela concepção, isto é, por intermédio do filho procriado" (MOREIRA, 1895, p. 37).
} 
Juliano Moreira evocava os princípios morais que deveriam reger o estabelecimento do matrimônio, cabendo ao homem a responsabilidade pelo conhecimento de sua doença e pela consulta ao médico. Entendia que, no caso da advertência deste último sobre as possibilidades de transmissão do mal, a falta de responsabilidade masculina deveria inscrever o sifilítico com criminoso. O que estava em jogo era a prescrição de uma delicada equação entre liberdade e responsabilidade individual, restrita aqui como relativa apenas ao universo masculino, a ser equacionada em prol do bem coletivo da saúde, com a ajuda da ciência.

Cumpre destacar que a representação particular que relacionava crime e sexualidade, numa espécie de sexualização do crime ou criminalização do sexo, não era própria apenas do discurso que permeava o tema da sífilis. Como sabemos, desde meados do século XIX todo um discurso médico sobre aborto e infanticídio relacionou a periculosidade à imagem da mulher. Dada a maior preocupação com a questão da mortalidade infantil, a mulher praticante de aborto ou de infanticídio só possuía como atenuantes para atos criminosos tão hediondos a constatação de fatores sociais desfavoráveis, de doença mental ou de preservação da honra familiar (NUNES, 1991, p. 63- 64). A partir dos anos 1870, o sentido dessa relação entre crime e sexualidade feminina seria, em grande medida, deslocado: a defesa da honra ou a pobreza e miséria incapacitantes para o cuidado da prole deixavam de ser atenuantes, e o discurso médico concentrava-se na natureza feminina doentia, que levaria a mulher à prática criminosa, resultado de sua constituição degenerada.

"Todas as mulheres têm uma só base constitucional, frágil e selvagem, que pode levar a esse tipo de atrocidade; o ódio materno que pode levar ao assassinato de um filho não é uma situação especial: é o sinal de uma falta de moralidade presente em todos os indivíduos do sexo feminino" (NUNES, 1991, p. 64).

No discurso de Juliano Moreira, entretanto, não encontramos nenhuma referência à maior degeneração física e psíquica intrínseca à mulher. A imagem da natureza feminina a tornava tão somente objeto do mal transmitido ao seu próprio organismo ou ao feto que carregava. Nas relações entre a sífilis e a instituição do casamento - esta moralmente recomendável naquela época caberia à mulher apenas a finalidade reprodutiva, sob o desígnio de seu marido e sem ter disponível para si meios sociais e morais que a permitissem escapar da doença venérea e do casamento com o sifilítico. Nos termos de Moreira, "e 
ela se for infectada, não se recorda de revoltar-se, nem requereria o divórcio se este lhe fosse facultado" (MOREIRA, 1895, p. 37).

Em relação à representação sobre a fisiologia sexual feminina, o discurso psiquiátrico de Juliano Moreira centrava-se na imagem e qualidades do útero. Segundo ele, o momento da concepção e do parto seria o mais danoso à mulher, seja pela falta de diagnósticos corretos com relação à "sífilis concepcional" transmitida pelo feto, seja pelas várias conseqüências que a doença acarretaria para a fisiologia do útero:

"a rigidez do colo [do útero] constituída pelo desaparecimento parcial dos feixes de fibras musculares lisas e pelo predomínio de um tecido fibroso denso e compacto, infiltrado de células linfóides, dão ao toque a sensação de um verdadeiro tecido de esclerose" (MOREIRA, 1895, p. 39).

Fundamentando-se no consenso entre "parteiros de todos os países", afirmava que o cancro sifilítico do colo do útero, desenvolvido durante a gestação, modificaria a "marcha normal do trabalho [de parto], prolongando, mesmo impedindo a dilatação regular do orifício uterino" (MOREIRA, 1895, p. 39), além da predisposição a "lesões específicas da placenta", "inflamações periuterinas", "febre sifilítica pós-parto", "eclampsia" e "traumatismos mais ou menos graves".

Interessante notar que as considerações de Juliano Moreira sobre a especificidade do feminino em relação ao acometimento da sífilis não estavam referidas a uma constitucionalidade degenerada da natureza feminina, tal qual enfatizada pelo conhecimento psiquiátrico da segunda metade do século XIX. Apesar de inúmeras controvérsias presentes nesse período, alienistas europeus, principalmente franceses, relacionariam a sede e natureza da histeria ao sistema nervoso, ao cérebro e à degenerescência. A difusão dessa abordagem entre os alienistas e médicos brasileiros se daria, sobretudo, a partir das três últimas décadas do século XIX. Nessa abordagem, a figura da histeria é dissociada da imagem do útero, permanecendo, no entanto, a afirmação da vinculação entre histeria e sexualidade da mulher e a compreensão teórica que relacionava a histeria às anomalias da sexualidade (ENGEL, 2001, p. 344). Tais anomalias estiveram circunscritas principalmente em representações sobre a ausência de relações sexuais (e, portanto, recusa ao exercício da finalidade reprodutora) e sobre os excessos sexuais, nos quais se incluíam as perversões. Segundo Engel (2001), o trabalho de renomados psiquiatras da época, como Esboço da 
Psiquiatria Forense, publicado em 1904 por Franco da Rocha, e as aulas professadas por Henrique Roxo durante o ano letivo de 1905, sobre "Moléstias mentais e nervosas", são exemplos desse tipo de visão.

O que se observa no texto de 1895 de Juliano Moreira sobre a sífilis, entretanto, é que sua análise sobre a relação entre doença mental e sexualidade parece diferir da de seus colegas psiquiatras. Para falar das qualidades particulares da sexualidade feminina, o psiquiatra baiano descartaria a idéia de degeneração e se apoiaria no discurso médico brasileiro difundido na primeira metade do século XIX em torno da imagem do útero ${ }^{10}$. Nesse discurso médico estabelecia-se marcante associação entre distúrbios mentais e a fisiologia da mulher, afirmando-se, por essa via, uma relação direta entre histeria feminina e útero. A histeria ${ }^{11}$ - doença mental atribuída especialmente à mulher - seria consequiência do frágil cérebro feminino, "dominado pelo útero e pelos instintos - e não pela razão -, crença que certamente não era atributo específico da ficção literária, uma vez que já possuía comprovação científica" (ENGEL, 2001, p. 346). O corpo feminino aparecia como mais permeável à histeria do que o organismo masculino, considerando-se inclusive sua maior predisposição em fases específicas como puberdade, gravidez e menopausa.

É bem verdade que, em Moreira (1895), as representações sobre doença mental são bastante pontuais: com relação à mulher, ficam apenas indicadas quando o autor menciona a possibilidade de ocorrência de "traumatismos mais ou menos graves" sem, contudo, qualificá-los. Com relação ao desenvolvimento infantil, são relatados apenas no final do texto os estigmas para a "metrópole do pensamento - o cérebro", tais como os retardamentos próprios dos imbecis e idiotas (MOREIRA, 1895, p. 41). De qualquer modo, mesmo sem se referir em nenhum momento à histeria ou a outro distúrbio psiquiátrico específico do universo feminino, são as representações em torno do útero que dão sentido e aporte a suas considerações teóricas sobre a saúde da mulher, não mencionando em nenhum momento o tema da degeneração.

Já em 1899, no artigo "Syphilographia: a syphilis como factor de degeneração", publicado na Gazeta Médica da Bahia, Juliano Moreira reforça muitas das considerações de seu texto anterior. Ainda que não se detenha na questão dos modos possíveis de transmissão da sífilis da mãe à prole, em nada refuta as considerações sobre o papel atribuído ao sexo feminino como corpoobjeto que veicula o mal através do útero. Suas observações clínicas revelam pormenores quantitativos sobre a gravidez, partos e abortos implicados na história 
de vida e doença de mulheres de sifilíticos. Os quatro casos apresentados são de indivíduos do sexo masculino, com detalhes sobre a contaminação de suas mulheres e de suas primeira e segunda gerações. Em dois casos a primeira geração de mulheres, filhas de sifilíticos que se casaram com homens sadios, não impediu a transmissão dos efeitos funestos do mal materno para a geração subseqüente. Nos dois outros casos em que os pais eram sifilíticos, as mulheres dos mesmos, descritas como sadias ou não, tiveram diversos abortos e partos prematuros.

O foco principal da argumentação de Moreira (1899), entretanto, como o próprio título já diz, é o da sífilis como fator de degeneração. Todo o esforço do autor estava a serviço da demonstração de que a sífilis poderia ser hereditária ou adquirida por contágio direito e indireto, mas que, em todos os casos, trazia consequiências deletérias às gerações futuras. "Mal grado ligeiros pontos fracos este caso de Boeck se me afigura o melhor possível para evidenciar a transmissão da sífilis à $2^{\circ}$ geração" (MOREIRA, 1899, p. 122).

É notável, contudo, que em suas considerações científicas sobre as possibilidades de degeneração pela sífilis, Moreira (1899) citaria apenas duas vezes a noção de raça ou categorias relacionadas, como "negro", "branco", "mulato", "miscigenação racial", dentre outras. A primeira menção feita pelo autor, logo em um de seus primeiros parágrafos, diz respeito à questão da sífilis em suas relações com a sociedade "não ser ela menos digna da atenção dos que estudam tudo que se refere aos fatores de desenvolvimento físico e intelectual das raças" (MOREIRA, 1899, p. 112). Em consonância com sua posição na querela sobre a relação entre miscigenação racial e doença mental, Moreira não atribuía ao primeiro termo dessa relação o mal da degeneração. O uso da categoria raças, no plural, servia muito mais como sinônimo de populações e povos do que como expressão de marcas diferenciais que qualificariam grupamentos de indivíduos específicos e os tornariam mais sujeitos à degeneração física e psíquica. Parece exemplar, neste sentido, o fato de que, na descrição subseqüente de casos clínicos que apresenta, em nenhum momento estivessem referidas marcas ou descendências raciais, apesar dos inúmeros detalhes físicos incluídos na descrição dos pacientes. "H., 4 anos de idade [...] muito pequeno [...] malformações ósseas múltiplas", "mulher de pequeno talhe, magra, completamente desdentada do maxilar superior", "menina de 8 anos de idade, anã", "H.G. sifilítico [...] apresenta várias cicatrizes consecutivas" são casos que revelam em minúcia as conseqüências nefastas da sífilis, sem que a elas fossem articulados traços relativos à origem e qualidades 
raciais dos indivíduos. As lesões que habitualmente seriam sintomas da infecção sifilítica eram relacionadas por Juliano Moreira a outros modos de qualificação físico-moral do humano - a microcefalia, a idiotia, a imbecilidade, as perostites, a erupção maculo-papulosa, os estigmas dentários e oculares - não sendo imputadas direta ou indiretamente à descendência ou miscigenação racial.

A segunda menção do autor visa exatamente a refutar as considerações sobre um caso de sífilis hereditária tardia, descrita por Laschewitz numa publicação alemã de 1878. Segundo Moreira (1899, p. 119), "Laschewitz inclinou-se a pensar que a sífilis paterna era em tal caso de causa hereditária, concluindo por opinar que a sífilis precisa ser estudada não só no indivíduo, mas na raça". Para Moreira, entretanto, teríamos aqui um caso de erro diagnóstico que não justificaria a inscrição no espectro da sífilis e a investigação sobre as causas raciais do mal.

\footnotetext{
"Ora não se tendo encontrado outros sintomas de heredo-sífilis no pai da criança, não sei se uma ambliopia que aparece isolada depois dos 40 anos pode ser considerada como sintomática da mesma heredo sífilis" (MOREIRA, 1899, p. 119).
}

Para Juliano Moreira, a inscrição da sífilis se fazia no espectro apenas de uma degeneração hereditária, não atribuída à miscigenação ou diferenças raciais, ainda que a investigação e comprovação científica revelassem, de todo modo, resultados funestos para o destino das populações em geral, isto é, para toda e qualquer população, independentemente de cor e nacionalidade.

\section{Doença Mental, Sexualidade e Raça: Rupturas e Continuidades Discursivas}

Alguns autores têm demonstrado as relações entre o pensamento psiquiátrico dos anos de 1920 e 1930 e o movimento eugênico de conotação racista, considerando-se dentre seus representantes o próprio Juliano Moreira, um dos fundadores da Liga Brasileira de Higiene Mental. Criada em 1923, essa instituição e todos seus colaboradores teriam sido mesmo incansáveis em professar medidas eugênicas que, aplicadas nas diferentes esferas da vida social, levariam ao necessário aprimoramento racial e social do brasileiro (COSTA, 1989, p. 84; PORTOCARRERO, 2002, p. 53). No que diz respeito especificamente à relação entre eugenia e casamento, as propostas de controle 
das uniões matrimoniais teriam transitado entre os pressupostos do determinismo biológico e os da influência do meio ambiente, permitindo uma conciliação entre teorias deterministas e teorias neolamarckianas que, de todo modo, debatiam sobre a questão racial (CASTAÑEDA, 2003, p. 913-914).

Entretanto, procuramos demonstrar que o pensamento psiquiátrico de Juliano Moreira, do final do século XIX até fins dos anos de 1910, em muito parece se diferenciar daquele que foi evocado e utilizado para dar sustentação ao movimento eugênico brasileiro a partir dos anos de 1920. As teorias psiquiátricas alemãs de cunho organicista que o influenciaram foram por ele "convertidas" num discurso antideterminista, contrário à inexorabilidade dos males gerados por nosso clima ou constituição racial. Na discussão que travou com o discurso psiquiátrico hegemônico de fins do século XIX, Juliano Moreira consideraria a degeneração tanto como doença mental da ordem dos indivíduos, relativa apenas às unidades orgânicas individuais, quanto um mal mais geral, ameaçador para toda a espécie humana - em ambos os casos, independente de raça, cor ou nacionalidade e, portanto, em nada impeditiva do desenvolvimento de um projeto civilizatório brasileiro. Os rumos que esse projeto trilhou, articulado a um nacionalismo extremado em que a idéia de um país civilizado estava implicada pela condenação de nossa miscigenação racial, parecem constituir um deslocamento em relação às idéias de Juliano Moreira produzidas até 1920.

As conotações acima referidas concedidas por Juliano Moreira à idéia de degeneração apareceriam ainda nos seus trabalhos que articulavam doença mental e sexualidade, por intermédio do tema da sífilis. Do mesmo modo, entretanto, também não encontramos nesses seus textos nem uma conexão entre a sífilis e a questão racial, nem referências à relação entre degeneração e natureza feminina como produtora de doença mental, apesar do pensamento psiquiátrico brasileiro de meados do século XIX discutir e difundir amplamente tais referências.

Em Juliano Moreira, o discurso sobre a sexualidade, em particular sobre a sexualidade feminina, estaria implicado por representações que, por vias distintas daquela da degeneração, não deixavam, entretanto, de estabelecer uma diferenciação entre gêneros e conferir um estatuto específico à sexualidade da mulher, com base em suas particularidades físico-morais naturais. Trata-se de um conjunto representacional centrado nos temas da "reprodução" e do "casamento", que refletia uma moralidade bem menos igualitária do que aquela 
que, contrária às determinações racistas, permeava o projeto para a civilização brasileira cunhado pelo psiquiatra baiano.

A novidade do pensamento de Juliano Moreira sobre essa temática, portanto, não estava situada na adoção de uma visada igualitária entre os gêneros, mas no modo como esse personagem da psiquiatria brasileira qualificava a sexualidade feminina. Em vez de caracterizá-la como naturalmente passível de degeneração (física e moral), tal como enfatizado no discurso médicopsiquiátrico de meados do século XIX, Juliano apoiava-se nas teorias médicas da primeira metade do século XIX, em que a imagem do útero era argumento central para a fundamentação das mesmas. Assim, ainda que não relacionando o tema da sexualidade feminina ao da degeneração, imprimia à primeira marcas diferenciais, fundadas na especificidade e importância da fisiologia uterina.

Entretanto, as representações sobre doença mental e sexualidade veiculadas por Juliano Moreira não devem ser avaliadas, isolada e retrospectivamente, através de nossas lentes contemporâneas. Elas devem ser entendidas tanto articuladas às teorias sobre doença mental e raça, quanto desvinculadas de uma leitura a posteriori que tende a tomá-las como prova cabal de um "atraso" do pensamento, tendo-se em vista os anseios de inclusão e igualdade social próprios da visão moderna de mundo. Ao contrário, ao analisarmos em conjunto as relações entre doença mental, raça e sexualidade no pensamento de Juliano Moreira, encontramos menos o retrato de uma posição "retrógrada" sobre esses temas e mais a expressão de um dos modos por intermédio do qual aqui se produziram, concomitante e paradoxalmente, formas específicas de construção social da igualdade e da diferença.

Trata-se, assim, da edificação de uma visão científica que se apoiava, num primeiro nível, na proposição universalista igualitária de inclusão da sociedade brasileira no conjunto das nações civilizadas. Nessa perspectiva, descartava a qualificação diferencial pela natureza das raças, ao mesmo tempo em que, num segundo nível, se valia de um discurso sobre a especificidade da mulher e sua fisiologia sexual, com a alocação da diferença no campo da sexualidade. Por essas vias, aparentemente contraditórias, Juliano Moreira produzia um modo científico de projetar a organização de nossa sociedade, pautada na igualdade racial e calcada na diferença sexual. 


\section{Referências}

CARRARA, S. A geopolítica simbólica da sífilis: um ensaio de antropologia histórica. História, Ciências, Saúde - Manguinhos, Rio de Janeiro, v. III, n. 3, p. 391-408, nov. 1996 / fev. 1997.

. Estratégias anticoloniais: sífilis, raça e identidade nacional no Brasil do entre-guerras. In: HOCHMAN, G.; ARMUS, D. (Org.). Cuidar, controlar, curar: ensaios históricos sobre saúde e doença na América Latina e Caribe. Rio de Janeiro: Fiocruz, 2004. p. 427-453.

CASTAÑEDA, L. A. Eugenia e casamento. História, Ciências, Saúde Manguinhos, Rio de Janeiro, v. 10, n. 3, p. 901-930, set-dez. 2003.

COSTA, J. F. História da psiquiatria no Brasil. Rio de Janeiro: Xenon, 1989.

DUARTE, L. F. D. O império dos sentidos: sensibilidade, sensualidade e sexualidade na cultura ocidental moderna. In: HEILBORN, M. L. (Org.). Sexualidade: o olhar das ciências sociais. Rio de Janeiro: Jorge Zahar, 1999. p. 21-30.

A psychopathia sexualis de Krafft-Ebing, ou o progresso moral pela ciência das perversões $-1^{\text {a }}$ parte. Jornal Brasileiro de Psiquiatria, Rio de Janeiro, v. 38, n. 2, p. 83-86, 1989.

A psychopathia sexualis de Krafft-Ebing, ou o progresso moral pela ciência das perversões $-2^{\mathrm{a}}$ parte. Jornal Brasileiro de Psiquiatria, Rio de Janeiro, v. 38, n. 3, p. 119-123, 1989.

ENGEL, M. Psiquiatria e feminilidade. In: DEL PRIORE, M. (Org.). História das Mulheres no Brasil. São Paulo: Contexto, 2001, p. 322-361.

FERREIRA, L. O. Uma interpretação higienista do Brasil imperial. In: HEIZER, A.; PASSOS VIEIRA, A. A. (Org.). Ciência, Civilização e Império nos Trópicos. Rio de Janeiro: Access, 2001. p. 207-224.

FOUCAULT, M. História da sexualidade. Rio de Janeiro: Graal, 1988.

. História da loucura. São Paulo: Perspectiva, 1978.

FOUCAULT, M.; SENNET, R. Sexuality and solitude. London Review of Books, p. 3-7, May-June 1981.

MAIO, M. C. Raça, doença e saúde pública no Brasil: um debate sobre o 
pensamento sanitarista do século XIX. In: MONTEIRO, S.; SANSONE, L. (Org.). Etnicidade na América: um debate sobre raça, saúde e direitos reprodutivos. Rio de Janeiro: Fiocruz., 2004. p. 15-44.

MOREIRA, J. A alimentação pelo arroz e o beribéri perante a observação dos médicos hollandezes. Gazeta Médica da Bahia, anno 30, n. 6, dez, p. 241-250, 1898 .

. Culpabilidade dos syphiliticos que se casam. Revista Médico Legal, Rio de Janeiro, anno 1, n. 1, p. 36-41, 1895.

Klinoterapia. Diffusão do seu uso, sua technica e resultados no tratamento das psychoses. Rio de Janeiro: Typographia Besnard Frères, 1901.

. Classificações em Medicina Mental. Archivos Brasileiros de Neuriatria e Psychiatria, anno 1, 1 trimestre, p. 93-115, 1919.

. Querelantes e pseudo-querelantes. Archivos Brasileiros de Psychiatria, Neurologia e Medicina Legal, v. 4, n. 1 e 2, 1908.

. Syphilographia: a syphilis como factor de degeneração. Gazeta Médica da Bahia, Salvador, anno 31, n. 3, p. 112-125, 1899.

MOREIRA, J.; PEIXOTO, A. Classificação das moléstias mentais do Prof. Émil Kraepelin. Archivos Brasileiros de Psychiatria, Neurologia e Sciencias Affins, anno 1, n. 2, p. 204-216, 1905.

. Les maladies mentales dans les climats tropicaux. Archivos Brasileiros de Psychiatria, Neurologia e Sciencias Affins, anno 2, n.1, p. 222-241, 1906.

NUNES, S. A. A medicina social e a questão feminina. Physis, Rio de Janeiro, v. 1, n. 1, p. 49-76, 1991.

ODA, A. M. G. R. A teoria da degenerescência na fundação da psiquiatria brasileira: contraposição entre Raimundo Nina Rodrigues e Juliano Moreira. Psychiatry On-line Brazil - part of The International Journal of Psychiatry, v. 6, n. 12, Dec. 2001. Disponível em <http://www.polbr.med.br/arquivo/ wal1201.htm>. Acesso em 14 jun.2004.

PORTOCARRERO, V. M. Arquivos da Loucura: Juliano Moreira e a descontinuidade histórica da psiquiatria. Rio de Janeiro: Fiocruz, 2002.

RODRIGUES, R N. Os mestiços brasileiros. In: AS COLETIVIDADES 
anormais. Organização, prefácio e notas de Artur Ramos. Rio de Janeiro: Civilização Brasileira, 1939. p.195-205.

ROHDEN, F. Uma ciência da diferença: sexo e gênero na medicina da mulher. Rio de Janeiro: Fiocruz, 2001.

VENANCIO, A. T. A.; CARVALHAL, L. A classificação psiquiátrica de 1910: ciência e civilização para a sociedade brasileira. In: JACÓ-VILELA. A. M. et. al. (Org.). Clio Psyché ontem: fazeres e dizeres psi na história do Brasil. Rio de Janeiro: Relume-Dumará, 2001. p. 151-160.

\section{NOTAS}

${ }^{1}$ Este texto é fruto do trabalho desenvolvido em conjunto com a prof ${ }^{a}$. Jane Russo (IMS/ UERJ), no projeto "A constituição do campo psiquiátrico contemporâneo: a psiquiatria biológica" e que, desde 2003, tem buscado compreender as relações entre doença mental e sexualidade, como parte do projeto integrado de pesquisa / CNPq "Sexualidade, gênero e família: rupturas e continuidades na experiência da Pessoa ocidental moderna", coordenado por Luiz Fernando Dias Duarte (Museu Nacional / UFRJ).

${ }^{2}$ Doutora em Antropologia Social pelo PPGAS/MN/UFRJ. Bolsa de pesquisador visitante CNPq / Fiocruz / Casa de Oswaldo Cruz. Professora do Programa de Pós-graduação em História das Ciências da Saúde / COC / Fiocruz. E-mail: anavenancio@coc.fiocruz.br

${ }^{3}$ Essa idéia mais geral sobre a importância de estudos que tomam como objetos concomitantes ciência e história, tendo-se em vista constituírem modos privilegiados de autoconstrução das sociedades ocidentais modernas, tem inspiração na palestra de Lilia Moritz Schwarcz, intitulada "História e Antropologia: relações de fronteira", proferida no dia 2 de setembro de 2004, na Casa de Oswaldo Cruz / Fiocruz.

${ }^{4}$ Não é de se estranhar, portanto, que a partir do solo comum de ênfase no indivíduo e na dualidade físico-moral, os temas da doença mental e da sexualidade tenham historicamente sido articulados como objeto pela psiquiatria. Ao menos desde fins do século XIX, com a publicação, em 1889, da primeira edição de Psychopathia Sexualis, do psiquiatra alemão Krafft-Ebing, a sexualidade aparece como tema nodal do conhecimento psiquiátrico (DUARTE, 1989).

${ }^{5}$ Em 1903 Juliano Moreira assumiu a direção do Hospício Nacional de Alienados, lá permanecendo até 1930. Incentivou a primeira lei federal de assistência aos alienados, promulgada em 1903, tornando-se diretor da Assistência Nacional a Alienados em 1911. Em 1905 fundou os Archivos Brasileiros de Medicina, juntamente com Antonio Austregésio e Ernani Lopes, e a 
Sociedade Brasileira de Psiquiatria, Neurologia e Saberes Afins, em conjunto com Afrânio Peixoto. No contexto internacional, participou de diversos congressos médicos, como o de Lisboa (1906), Amsterdã e Milão (1907), Londres e Bruxelas (1913).

${ }^{6}$ Dentre seus trabalhos, podemos citar "Pasteur" (1895), "Existe na Bahia o Botão de Briska?" (1895), “Distribuição Geographica do Botão Endemico dos Paizes Quentes” (1985), “A alimentação pelo arroz e o beriberi perante a observação dos médicos hollandezes" (1898) e “Os mosquitos e a Malária”(1899).

${ }^{7}$ São representativos dessa fase os trabalhos "A clínica psiquiátrica da Universidade de Leipzig" (1901), “A clínica psiquiátrica e de moléstias nervosas na Universidade de Halle" (1901) e "A clínica psiquiátrica e de moléstias nervosas na Universidade de Wirtzburgo" (1902), dentre vários outros.

${ }^{8}$ É a partir desse sentido físico-orgânico concedido à vontade que podemos entender a referência que Juliano Moreira e Afrânio Peixoto fazem às chamadas intoxicações crônicas, dentre as quais "somente se ocupou o Prof. Kraepelin das denominadas voluntárias: alcoolismo, morfinismo e cocainismo" (MOREIRA e PEIXOTO, 1905, p. 213 - grifo meu).

${ }^{9}$ Como interno na Faculdade de Medicina da Bahia, adquiriu, em 1891, o grau de doutor, com a tese "Sífilis Maligna Precoce". Publicou, respectivamente, em 1895 e 1899, os artigos que serão aqui analisados: "Culpabilidade dos syphiliticos que se casam" e "Syphilographia: a syphilis como factor de degeneração". Durante esse período, Juliano Moreira foi professor substituto da Seção de Doenças Nervosas da Faculdade de Medicina da Bahia, após defender a dissertação "Disquinesias Arsenicais", dedicando-se concomitantemente à dermatologia e à neuropsiquiatria.

${ }^{10}$ Rohden (2001), ao analisar as teses da Faculdade de Medicina do Rio de Janeiro no período de 1833 a 1940, nos dá a medida da ênfase do discurso médico sobre temas referentes à sexualidade e à reprodução. Destaca que, na grande maioria desses trabalhos, é a vida feminina que aparece problematizada pela medicina, construindo-se, por essas vias temáticas, uma ciência da mulher.

${ }^{11}$ Desde a tradição médico-hipocrática e da medicina da Idade Média, a histeria já era considerada como "manifestações independentes de um útero que agiria como um animal oculto no interior do organismo" (ENGEL, 2001, p. 343). 
Mental Disease, Race, and Sexuality in the Psychiatric Theories of Juliano Moreira

Taking as the point of departure the academic image of Juliano Moreira as the founder of scientific psychiatry in Brazil, this study analyzes the concepts he expressed on mental disease, race, and sexuality. His theories constituted a sui generis transposition of the thinking of German psychiatrist Emil Kraepelin, aiding in the construction of the ideals in defense of the Brazilian civilizational process in the early $20^{\text {th }}$ century. He based his concepts on organicist premises, while arguing against the then-prevailing notion of so-called unfavorable "natural" Brazilian conditions such as climate and race. Analyzing the work published by Juliano Moreira until 1920, one sees how his scientific discourse discussed the theme of sexuality, expressed under the label of "syphilis", "reproduction", and "marriage". On this point, Juliano Moreira did not resort to the idea of a degenerated female nature, increasingly widespread in the mid- $19^{\text {th }}$ century. Although he did not rule out the more general notion of degeneration, pertinent only to the level of individual organic units, he did rule out the correlation between degeneration and female nature to focus on the hegemonic medical foundations of the first half of the $19^{\text {th }}$ century, which linked differential female characteristics and female sexual physiology, represented paradigmatically by the image of the uterus.

Key words: Race; sexuality; mental disease; psychiatric science; Juliano Moreira.

Recebido em: 30/09/2004.

Aprovado em: 28/10/2004. 